\title{
Acute toxicity and teratogenic impacts of construction waste runoff on zebrafish embryo
}

\begin{abstract}
Construction waste is on rise in developing country; heavy metals in construction waste may harm environment and residents. The aim of this research was to study the toxicity and teratogenicity of construction waste runoff by using zebrqfish embryo. The heavy metal analysis shows that the concentrations of $\mathrm{Hg}, \mathrm{As}, \mathrm{Cd}, \mathrm{Cr}, \mathrm{Cu}, \mathrm{Ni}$ and $\mathrm{Pb}$ have exceeded the Malaysian Water Quality Standard. At 100\% runoff, 92\% and 74\% of the zebrqfish embryo showed curve trunk and head malformation respectively, and yolk sac edema (19.8 $26.1 \%)$ and pericardial edema $(61.5 \pm 0.86 \%)$. This suggest that construction waste runoff was contaminated with heavy metals and teratogenic.
\end{abstract}

Keyword: Construction waste; Runoff; Heavy metals; Zebrqfish embryo; Teratogenicity; Toxicity 